\title{
A Comparison of the Grammatical Production of Child Heritage Speakers of Spanish across Language and Grade: Kindergarten and Grade 1
}

\author{
Estrella Rodriguez ${ }^{1, *}$, Kristina Bustamante ${ }^{1}$, Carla Wood ${ }^{1}$ and Gretchen Sunderman ${ }^{2}$ \\ 1 School of Communication Science and Disorders, Florida State University, Tallahassee, FL 32306, USA; \\ knr15c@my.fsu.edu (K.B.); carlawood.fsu@gmail.com (C.W.) \\ 2 Department of Modern Languages and Linguistics, Florida State University, Tallahassee, FL 32306, USA; \\ gsunderman@fsu.edu \\ * Correspondence: ecrodriguez@fsu.edu
}

Academic Editors: Maria del Carmen Parafita Couto, Usha Lakshmanan and Osmer Balam Received: 28 June 2017; Accepted: 27 November 2017; Published: 13 December 2017

\begin{abstract}
In this study, we elicited grammatical forms (oral production) from a group of child heritage speakers of Spanish $(N=45)$ in English and Spanish, using the morphosyntax subtest of the Bilingual English-Spanish Assessment (BESA), (Peña et al. 2014). A cross-sectional design was used with 25 participants in kindergarten and 20 in first grade. All children spoke Spanish at home and attended English rural schools. We controlled for L2 class environment and socio-economic status. Research findings indicated children produced more target structures in L1 Spanish. This project supports the view that sequential bilingualism and continuous exposure to the heritage language may assist heritage speakers to maintain some L1 structures (Miller and Cuza 2013; Pascual y Cabo and Gómez Soler 2015). Patterns of L2 development are also addressed.
\end{abstract}

Keywords: bilingualism; heritage speaker; passive sentence; progressive; subjunctive

\section{Introduction}

Heritage Speakers (HSs) are, by definition, bilingual individuals who manage to communicate in two languages. They have been exposed to the native language of one or both parents from birth [1], and may display superior oral proficiency in the heritage language which is usually spoken in the household [2,3]. The contexts in which HSs continue to use the heritage language and the social majority language at home and/or at school can affect their linguistic trajectory in either language and their resulting bilingualism proficiency [4-6]. In particular, continuous exposure to the heritage language at home and in the community may favor a semantic context in which the child extends use of certain L1 structures [6] and this despite rising formal instruction in the social majority language, the L2.

Sometimes the eventual shift to the language of instruction can be associated with deceleration of growth in the home language, the L1 $[7,8]$. However, even if there could be a linguistic dominance shift early in life, HSs still easily communicate in the household language with friends and extended relatives later in life. They tend to remain functional bilinguals.

Most of the research on HSs has looked at different linguistic preferences that set them apart from traditional native speakers of the heritage language and also from learners of the heritage language (L2 learners). HSs are unique in their patterns of language use. Their linguistic use in childhood or later years may depend on the specific context of acquisition and/or developmental difficulties related to a specific structure $[9,10]$. They have a different situation compared to L2 learners, who grow up with the majority language and may learn a minority language in adulthood [11-15]. These authors have 
examined grammatical and syntactic comprehension and production patterns in adult HSs, and they have found HSs display their own preferences Sometimes they behave like native speakers in terms of their implicit linguistic knowledge, while other times they show preferences for a given structure which resembles the performance of L2 learners. They may behave neither entirely native-like nor totally L2 in linguistic and grammatical knowledge.

However, little is known about the characteristics of young HSs who are starting to receive formal instruction in the social majority language, around age 5. In particular, there is a gap in the literature on the analysis of the oral verbal production by young HSs in the early grades. There is also the issue of linguistic variation among HSs themselves. The intravariability in HSs has been investigated by several authors $[5,12,14,16]$, among others. Some of the differences in linguistic proficiency in given groups of HSs may be due to differential literacy levels in the heritage language, and to the degree of its use at home and in social contexts [17].

Grammatical knowledge among groups of HSs varies, since linguistic and social experiences with the heritage language itself are different for every heritage speaker. Connected with early onset age of bilingualism, heritage L1 grammatical systems may undergo either incomplete acquisition, loss of forms (attrition) or linguistic contact acquisition starting in childhood. Any combination of the three situations is also possible [15]. Considering the intravariability among HSs themselves, this study examines verbal production in five- to six-year-old HSs. We looked at verbal production in the home language (Spanish) and in the official language of instruction (English) when the children are early in school age, in kindergarten (KDG) and grade 1 (G1).

We were motivated to investigate possible differences in L1 and L2 verbal production from one academic year to the next. Provided evidence that differences emerge at this early stage, future research investigating L1 form loss, or L2 assimilation would warrant investigation. Such topics are hypothesized to be issues present in bilingual language development, but lack robust evidence in young HSs starting instruction in the social majority language.

We also wanted to explore how verbal production in English (L2) may reflect grade differences between KDG and G1 participants. Findings related to L2 differences would motive future longitudinal research examining L2 developmental trends in these young Spanish HSs. In the following pages, we present a review of the literature on young heritage grammatical and syntactic knowledge and a formal description of the structures we tested with the young HSs. The review is followed by a description of the literacy measures administered and the holistic assessment used to measure verbal production in both languages. We then present the results and provide implications for future heritage research at the end of the manuscript.

\section{Heritage Grammatical Knowledge: Variability in Early and Late-Acquired Structures}

Studies that have analyzed the linguistic performance of young HSs usually compare them to the performance of monolingual peers $[2,11,18]$. Traditional native speakers have been used as a control group in the L1, since they have grown up monolingual with formal instruction in their native language. Research studies indicate that HSs do not behave entirely native-like, but they do mirror traditional monolingual peers in some contexts, especially with regards to early acquired vocabulary and grammatical content that is sustained in everyday practice $[3,19,20]$. We present some investigations that have analyzed heritage representation of syntactic properties in the heritage language with early (gender) and late acquired features (mood and passivity).

\subsection{Young Heritage Gender Knowledge in the L1}

Cuza and Pérez-Tattam analyzed gender selection and phrasal word order in the production data of 32 Spanish-English children aged 5-10 and born in the United States [21]. Their answers on a picture naming task were compared with the answers of Spanish monolingual peers of the same age. Results indicated the bilingual children had begun to adapt the patterns of the social dominant 
language. They had more frequent errors in gender mismatch and phrasal word order in comparison to the monolingual group.

Cuza and Pérez-Tattam's study lends support to the Feature Re-Assembly Approach for L2 acquisition [22], adapted to child heritage speakers of Spanish [21,22]. As children were restructuring the unique morphological features of Spanish (gender agreement) into the emerging weaker agreement features of L2 English, they overextended the use of the masculine gender. They did not recognize feminine gender as a marked or a differential gender form of Spanish. In pointing out the limitations of their findings, the authors conceded similar patterns observed in participants had resulted from a homogeneous heritage sample from similar socio-economic backgrounds. They suggested undertaking research with more linguistically diverse heritage groups to investigate intra-variability in heritage grammatical knowledge.

Montrul and Potowski also investigated the acquisition of gender marking rules in younger (6-8 years old) and older bilinguals (9-11 years old) enrolled in a Spanish-English immersion program [23]. 38 of all participants were from Spanish-speaking homes (HSs) and 22 of the participants came from English-speaking homes (L2 Spanish learners). A group of 29 monolingual children in the same age groups from Mexico were the Spanish controls [23]. All participants completed an oral narrative of a popular fairy tale story and a picture elicitation task. Results of both tasks indicated the HSs made more gender errors than the traditional native speakers, though they surpassed the L2 learners in accuracy. Montrul and Potowski found no evidence of L1 language loss in Spanish with increased heritage age [23].

\subsection{Young Heritage Mood and Passive Knowledge in the L1}

Silva-Corvalán documented features of the acquisition of Spanish by third generation children, also young HSs [20]. She looked at language development in natural conversations in the heritage language of two children from her own family (ages 2 and 6), whose input in Spanish was provided by one of the parents and one grandparent. Despite the fact that children had greater proficiency in English than in Spanish, they were able to converse in Spanish on a variety of situations. The young participants were able to produce clause combinations and most verb tenses of the indicative in the heritage language. Only the older child had instances of the present and imperfect subjunctive in his speech by age 5, which does suggest the complexity of some properties of the subjunctive [20].

When comparing the children's linguistic properties with those of two adult HSs, Silva-Corvalán noted important similarities between both groups [20]. Common properties signaled an incomplete tense, mood and aspect Spanish system in the heritage grammar, regardless of age group. The author has called for sustained exposure to the heritage language. The children of her study were later enrolled in Spanish-immersion, and it contributed to the ongoing expansion of the heritage language, which otherwise would have been interrupted by age 5 , or around school entrance.

To understand heritage subjunctive mood production, we must go back to L1 acquisition patterns in which complex linguistic features may be acquired in a certain fashion or order. Spanish mood, for example, may be acquired and used first with verbs of volition and indirect commands out of which a specific outcome is desired or expected, while other properties particularly related to mood-such as relative clause use may appear later in the L1 [6,24]. Other features, such as the passive voice use may pose further difficulties in many languages.

Passive voice production is more complex than the subjunctive in that it involves marked morphological ('-en') and syntactic (by-phrase) constructions [25]. In Mitkovska and Bužarovska's distinction of be-passives from get-passives, they support other findings that canonical passive features (explicit or implicit agent, and active counterparts are often missing in get-passives [25-28]). The work of Bruhn de Garavito and Valenzuela in Spanish recognizes that there are two different passive constructions: the eventive passive with the copula ser ('to be') and the adjectival passive with estar ('to be') [29]. Spanish also has impersonal passives with the particle se (the impersonal particle 'one' as a marker of passivity), though in general Spanish does not have a preference for use of the passive 
voice at all like English does [30,31]. In L1 Spanish the active voice is preferred. Through the work of Silva-Corvalán, we know that young HSs use Spanish subjunctive in their early interactions, but they may avoid instances of a more complex structure such as passives [20].

In this project, we investigate young heritage verbal production with three different grammatical structures that vary in developmental terms. One of them, the progressive, was chosen because it is early acquired in both Spanish and English and it exhibits a similar structural form in both languages (auxiliary + gerund). Some properties of the other two chosen structures (L1 Spanish subjunctive and L2 English passive) are late-acquired. The Spanish subjunctive is used much more than the Spanish passive voice, and is not as late-acquired as passives. English passives are more abundant than the modality existing in English to express subjunctive mood. We were particularly interested in documenting verb form production in young heritage children through a bilingual assessment when children are in the early grades of school instruction in the majority language.

\subsection{A formal Description of the Structures Tested in the Oral Production Task}

We decided to focus on verb morphology, as it has been observed to be stable overall in HSs [3,32]. We begin by examining the progressive. The progressive structure in both languages is used to refer to an action in progress at the moment of speaking in present or past tense. Semantically, there are also differences between both languages. In Spanish the progressive can be expressed with a non-progressive form, as in Los niños nadan ('They swim') instead of Los niños están nadando ('They are swimming'). The two are virtually interchangeable and compatible [32]. In English, however, the use of the progressive is obligatory for reference to simultaneous actions. The progressive in English is more temporarily restricted [32,33].

In terms of the syntax, the auxiliary heads the verb phrase (VP) in both languages in the progressive form. In Spanish the auxiliary is a dependent argument in the form of the verb estar; while in English the auxiliary is the verb to be and it represents a specifier of the main verb [34,35]. Auxiliaries in both languages contain person and number features. Even when these features are stronger in Spanish (estoy, estás, está, etc.), English also exhibits them ('am', 'are', 'is'). Giorgi and Pianesi observe that English auxiliaries follow a paradigm and will move overtly in the syntax (as they do in Spanish) facilitating early acquisition of the structure [24]. The verb 'to be' in English also distinguishes person morphology both in present ('am', 'are', 'is') and in the past ('was', 'were').

As to the other component of the verbal progressive form, the gerund, Spanish has two ending morphemes (cantando, comiendo) with a few irregular verbs. English verbs take the '-ing' form ('singing', 'eating') to indicate progressive actions. Semantic differences in its use, a similar structural composition in the progressive, early acquisition, and the presence of features in the auxiliary verb in both languages led to its selection as a structure of interest to compare in the L1 and the L2 with young HSs starting to receive instruction in the majority language.

The Spanish subjunctive was also chosen as part of the study, and it is certainly more complex than the progressive. In English, the subjunctive is rarely used, as it is residual. In Romance languages, however, it is a common choice with volitional verbs [24]. It is formed with a main clause and a dependent clause that may contain indicative or subjunctive mood. If an indirect command or a suggestion is part of the main clause, native speakers know that subjunctive (and not indicative) is to be expected in the dependent clause. Therefore, a preceding clarifying context in the main clause may aid Spanish speakers in the oral or written production of the structure. In terms of morphological characteristics, Spanish distinguishes it according to infinitive root (... que estudie, ('that s/he study') ... que coma, ('that s/he eat') ... que duerma, ('that $\mathrm{s} /$ he sleep') etc.). In spite of appearing in a dependent clause, the subjunctive is very much used in everyday situations to offer recommendations and as part of indirect speech [20].

The last structure chosen as part of the oral production task was the English passive voice. This is the most complex of the three. While the order of sentential components is stable and predictable in the progressive and in the Spanish subjunctive, passive sentences may be ambiguous. The word order 
changes when a sentence undergoes a transformation from active to passive voice. Passivity is achieved when the functions of subject and agent are reversed, which makes the passive more difficult to parse (let alone produce) than the active construction. In any language, passives generally involve the acquisition of argument structure [10]. Aside from the semantic and syntactic complexity of passives, the English language adds a passive particle in the auxiliary ('was', 'were') with dynamic features of number and person in the syntax, as previously discussed in this section. Add a by-phrase construction, and the result is that the passive voice is more complex than the other two structures. The overall meaning of the main verb does not change from active to passive transformation. There must be control in using the sentential elements to indicate passive content [36]. Due to learnability difficulties and the fact that the passive is usually late-acquired, we anticipated passive sentences would be the most difficult to produce by young child heritage speakers of Spanish. We wanted to compare its production with the subjunctive, which is more prevalent in the L1.

\subsection{Investigating Progressive, Subjunctive and Passive Voice Use in L1 Spanish and L2 English}

We compared English and Spanish verbal production of young HSs who speak Spanish at home and are in early stages of English instruction in the regular school system. We first compared their production in English and Spanish using the progressive tense in KDG and in G1. The progressive forms are among the earliest to develop in morpheme acquisition order for both L1 English and L1 Spanish children $[37,38]$. Progressive ('-ing') is an early-acquired structure.

Studies on the natural order of acquisition support views that grammatical morpheme acquisition is predictable in the L1 and the L2, with the progressive being acquired earlier than other morphemes [39]. The progressive also shares structural similarities between both languages by employing an auxiliary verb and a morphologically inflected main verb; the gerund in Spanish, participle in English [40]. However, there are also differences in how the progressive is used in both languages due to semantic differences. The progressive in Spanish connects in distribution to the present tense, and the latter is sometimes chosen by Spanish native speakers over the ongoing aspect of the progressive to describe an action in progress. HSs may also display this preference, behaving like traditional native speakers in their overextension of the present tense in an ongoing context [21,41].

In English, however, there is no use of the present tense instead of the ongoing progressive [32]. The progressive marks simultaneous or progressing events, and the progressive is also grammatical to demark future events, which is not the case in Spanish [40]. In some adult HSs with long L2 exposure, English transfer may influence use of the progressive over the present tense in Spanish [41]. There could be variability in structure use within HSs. In this study, both Spanish and English progressive forms behave similarly in the section of the Bilingual English-Spanish Assessment (BESA) with dynamic verbs, and so we were motivated to investigate any L1 or L2 preferences in young HSs. Examples featuring the progressive tense taken from the BESA are displayed below in (1) and (2). The item numbers and sequence were modified from the BESA for our examples here. These items are accompanied by pictures in the BESA.

1. Q. María and Juan want to skate. They are doing it now. What are they doing here? They ...

A. (are skating).

2. Q. Los niños van a nadar. Lo están haciendo ahora. ¿Aquí, qué están haciendo? Los niños ...

A. (están nadando/nadan).

'The children are going to swim. They are doing it now. Here, what are they doing? The children ...' (are swimming/swim).'

Along with the progressive form, we also looked at production of two generally late-acquired structures: Spanish subjunctive in the L1 and English passive sentences in the L2. The Spanish subjunctive and the English passive voice are very different structures. The subjunctive surfaces early in Spanish and as mentioned earlier on, it is very much used with verbs of volition and to signal 
indirect commands [19,42]. The Spanish subjunctive can emerge late in the L1 when it connects to adverbial clauses and complex subordinations [6]. The proportion of subjunctive forms produced by traditional native Spanish speakers is low. It represents about 7.2\% of all Spanish verb forms [43]. The subjunctive first surfaces in L1 Spanish as early as the second year of life, but stabilizes in accuracy towards ages 5-7 [44]. Errors with the subjunctive in simultaneous Spanish-English bilingual children have also been reported as minimal during heritage language interactions [20].

English passives, on the other hand, tend to be late-acquired and are developmentally complex, but have a high frequency of usage in written English. Findings of variability in adult English natives' and nonnatives' comprehension of English passives supports usage-based theories of linguistics [45,46]. Passives' dominant presence in writing versus oral language is hypothesized to interact with individuals' amount of educational experience and English proficiency to predict ultimate attainment. In general, passives have a complex syntax in any language, and may require more processing in oral or written production when compared to active sentences.

In actives, the relationship between grammatical and thematic roles is direct. The subject is the agent and the performer in the verb action. In passive sentences, this relationship is altered. When presented with the first noun, the parser assumes it is the subject of the sentence. The verb that follows in English only accentuates that quality. If there is a second noun phrase after the verb (as part of a by-phrase (see [47]), the parser would assign it a passive role $[47,48]$. The first noun phrase may be re-analyzed or interpreted differently depending on the verb action. This is the reason why the passive voice is late acquired in both languages. It is usually in place by age $7[10,49]$.

The passive and subjunctive are interesting to study together in young HSs since they are both residual structures in one of the HSs' languages. The Subjunctive in Spanish has a higher frequency of occurrence when compared to the Spanish passive voice. Traditional native Spanish speakers prefer use of the active voice instead. Passives are more common in written English, and their use in the oral language is minor. Thus, we were interested in examining subjunctive and passive voice production in young HSs to document production patterns from one academic year to the next. Examples of BESA sentences targeting these constructions are provided below in (3) and (4). The item numbers and sequence has been modified from the BESA for our examples.

3. Q. The girl is pushed by the boy. What happened to the boy here?

A. (The boy is/was pushed by the girl).

4. Q. La mamá quiere que se peine. ¿Y aquí, qué quiere la mamá? La mamá ...

A. (quiere que se lave los dientes).

'The mom wants that the child brush her hair. Here, what does the mom want? The mom ...' (wants that the boy brush his teeth).'

We now proceed to describe the study methodology, the participants and the BESA assessment in more detail.

\section{Materials and Methods}

\subsection{Study Design}

The data presented in this project are part of a larger study funded by the US Department of Education Institute for Educational Sciences, Project BLOOM Grant No. R305A130460. All participants' parents gave their informed consent for inclusion before their children participated in the study. The study was conducted in accordance with the Declaration of Helsinki, and the protocol was approved by the Ethics Human Subjects Committee of Florida State University (HSC \#2013.10536 and HSC \#2014.13020). The larger study involved an enhanced electronic vocabulary intervention. The vocabulary treatment provided scaffolded explanations in L1 Spanish to bridge vocabulary knowledge into L2 English. Vocabulary lessons were presented in the form of e-books. Participants 
were selected from two rural schools enrolled in the intervention study which had completed the BESA assessment (see Section 3.2) at the time of our data analysis.

All student data included in the present analysis were collected prior to student engagement in the vocabulary intervention for the corresponding school year. Two KDG through G1 cohorts were considered for participation. The first cohort began KDG in 2013 and the second cohort began KDG in 2014. Many students in both cohorts had complete data for only the KDG or G1 school year due to a shortage of research assistant personnel. Therefore, a cross-sectional design was chosen to maximize the extant data.

Participants from both cohorts were divided into either a KDG or G1 group. No child was included in both groups. All G1 students had received the e-book intervention during the KDG year. Student data was excluded from the present study if they had not received assessment with the verbal production instrument (BESA) during either grade. This occurred because of a shortage of Spanish-speaking research assistants $(n=11)$. Students were also excluded if they displayed inability to respond to one of the BESA assessment languages $(n=1)$. Overall, the sample reported in this paper includes 45 students ( $25 \mathrm{KDG}$, and $20 \mathrm{G1}$ ) who responded to the BESA assessment. Children responded to the semantic and morphosyntax portions [50].

\subsection{The Bilingual English-Spanish Assessment}

The BESA was designed to assess bilingual Spanish-English child language development [50]. It was normed on a United States sample that included 16 dialects. English and Spanish subtest items were selected based on the linguistic characteristics of each language and cultural practices of bilingual Spanish-English children. Therefore, the subtests are not direct translations from either language. Authors report the split-half reliability over all ages four through six to be 0.96 for the morphosyntax subtest, indicating high test internal consistency.

The morphosyntax subtest is composed of two parts. Part 1 is a cloze item task where an examinee listens to a prompt and completes a sentence verbally. Part 2 is a sentence repetition task where an examinee listens to a sentence and repeats the sentence verbatim. We quantified young heritage child answers to Part 1 (cloze item task) and Part 2 (sentence repetition task). We will present results from Part 1 only, the cloze item task, as Part 2 is part of another investigation within the BLOOM project.

Though there were other linguistic properties targeted in the BESA assessment; namely articles, possessive forms, plurals, and present tense in the third person singular, we document verbal production with progressive, subjunctive and passives only. Both Spanish and English subtests include items targeting the progressive form. As stated earlier, the Spanish present tense may be used instead of the progressive by Spanish native speakers, while in English the ongoing nature is preferred by native speakers to refer to a progressive action. The English subtest contains one demonstration item targeting the present progressive and three test items (two cloze items, one sentence repetition) targeting the present or past progressive structure. An example is provided in Example 1. The Spanish progressive subtest contains two demonstration items and three test items (cloze items) with present progressive (estar + gerund), as seen in Examples (5)-(8). Again, the item question numbers and sequence has been modified for these examples. 
Example BESA Items Targeting Examined Grammatical Productions

5. English BESA Morphosyntax Progressive Cloze Task and Demonstration Items

Q. María and Juan want to skate. They are doing it now. What are they doing here? They ...

A. (are skating).

6. Spanish BESA Morphosyntax Progressive Cloze Task Demonstration Item

Q. Los niños van a nadar. Lo están haciendo ahora. ¿Aquí, qué están haciendo? Los niños...

'The children are going to swim. They are doing it now. Here, what are they doing? The children ...'

A. (están nadando/nadan). (are swimming/swim).'

7. English BESA Morphosyntax Passive Voice Cloze Task Demonstration Item Q. The girl is pushed by the boy. What happened to the boy here?

A. (The boy is/was pushed by the girl).

8. Spanish BESA Morphosyntax Subjunctive Mood Cloze Task Demonstration Item Q.

Q. La mamá quiere que se peine. ¿Y aquí, qué quiere la mamá? La mamá ...

'The mom wants that the child brush her hair. Here, what does the mom want? The mom ...'

A. (quiere que se lave los dientes). (wants that the boy brush his teeth).'

As part of the BESA, we also investigated production of the Spanish Subjunctive and the English Passive Voice in the young HSs. Even if the subjunctive is more prevalent in Spanish than the passive voice, and the passive in English is more complex overall, we wanted to document young heritage verbal production in the two languages. It would not have been possible had we selected other test items from the BESA (plurals, possessives, articles). In the BESA cloze item task, the English passive voice subtest contains two demonstration items and three test items (all cloze items) targeting the passive voice with the auxiliary and regular/irregular verbs, as seen in Example 3. The Spanish subtest contains two demonstration items and six test items (four cloze items, two sentence repetitions). All Spanish subjunctive items contain verbs of volition, as in Ella quiere que ... ('She wants that ... ') for all six test tokens (Example 4). In the subjunctive section, some Spanish verbs were reflexive (Example 4), and others were not [50]. We did not control for reflexive use in the study. Administration of all cloze items in each language was typically completed in approximately $12 \mathrm{~min}$. The Spanish battery was completed on a given day. The English subtest was completed on a different testing day. Participants were allowed to take breaks as requested.

\subsection{Standardized Assessments as Part of the Literacy Intervention Testing}

All participating children were tested at the beginning of the grade year on a variety of vocabulary and syntax measures before the e-book intervention was to take place for that given school year. The first measure, the Peabody Picture Vocabulary Test-4 (PPVT-4) is an instrument used to assess children's receptive vocabulary understanding in English [51]. It is a norm-referenced measure of receptive vocabulary in English (normed for 2 to 90 years). The assessment takes 10 to $15 \mathrm{~min}$ to administer and upon hearing a word, the child is asked to point to a picture given a choice of four (e.g., Show me "laughing"). The measure was normed on 3540 individuals in the United States reflecting the US population distribution with regard to sex, race/ethnicity, geographic region, socioeconomic status, and clinical diagnosis.

Participants were also tested on the Woodcock Reading Mastery Tests, Third Edition (WRMT-III) [52]. The WRMT-III is a set of English literacy tests for measuring oral language and academic achievement normed on individuals ages 4 through 79 years of age. The test takes approximately five minutes per subtest. Some of the subtests of the Woodcock include letter identification, word identification and rapid 
automatic naming of letters and numbers. The test's validity was based on normative data gathered on than 3360 individuals (including 2600 school age participants) in 45 states in the United States.

The Test de Vocabulario en Imágenes Peabody (TVIP) was also administered to participants as part of the pre-intervention assessments [53]. The TVIP is a Spanish language version of the PPVT-4, a norm referenced measure of receptive vocabulary in Spanish designed for children ages 2 years 6 months through 17 years 11 months. The TVIP takes 10 to $15 \mathrm{~min}$ to administer as the child is asked to point to a desired picture given a choice of four that the tester utters in Spanish. The TVIP was normed on 2707 monolingual Spanish-speaking children from Mexico and Puerto Rico. Weighted scores were used to correct the uneven socio-economic status distribution according to the US census. Median reliability was 0.93 .

As seen in Table 1 participants scored higher on the TVIP (Spanish receptive vocabulary) when compared to the PPVT (English receptive vocabulary) though the difference was not significant.

Receptive tokens on the PPVT English measure have proven challenging in some contexts for bilingual children when tokens reflect a home context in which the heritage child may communicate more in Spanish as opposed to those tokens from a school context that all children share in school while receiving instruction $[54,55]$.

Table 1. Child Performance on Standard Tests-Peabody Picture Vocabulary Test, Test de Vocabulario en Imágenes Peabody (TVIP) and Woodcock Johnson (WJ) $(N=45)$.

\begin{tabular}{cccc}
\hline & \multicolumn{3}{c}{ Normative Assessments } \\
\cline { 2 - 4 } & $\boldsymbol{N}$ & $\boldsymbol{M}$ & $\boldsymbol{S D}$ \\
\hline PPVT & 45 & 82.4 & 12 \\
TVIP & 45 & 88 & 19.40 \\
WJ Letter Identification & 44 & 95.8 & 16.2 \\
WJ Phoneme Awareness & 44 & 81.7 & 18.4 \\
WJ Rapid Automatic Naming & 40 & 89.7 & 12.6 \\
WJ Reading Readiness & 38 & 85.3 & 13.4
\end{tabular}

Note: $85-115$ is considered to be within average range when compared to the normative expectations for monolingual English speaking peers of the same age.

\subsection{Research Questions}

The following research questions were formulated:

1. Do children produce earlier (progressive) structures in Spanish (L1) or English (L2)?

2. Do they produce more subjunctive forms in Spanish, or more passive sentences in English? (later-acquired structures)

3. Are production patterns similar or different between KDG and G1?

Our hypotheses for the research questions were based on the structural complexity and semantic usage of each structure. For the first research question, we hypothesized that young HSs would be more productive with progressives in the L2 versus use of the L1 progressives. We predicted young HSs would be influenced by the ongoing nature of the progressive tense in English which refers to simultaneous actions exclusively. In Spanish the use of the progressive is ambiguous, since the simple present can indicate both simultaneous and habitual actions and can be used instead of estar with a gerund to refer to actions coexisting with speech time [32]. Therefore, we hypothesized the young HSs would use the progressive in Spanish less than in English, since in Spanish it tends to occur in fewer contexts.

In terms of developmental differences, we predicted G1 production of progressives in both languages would surpass KDG production for the same structures due to continuous exposure to English and Spanish for an additional academic year.

As to the remaining structures (subjunctive and passives), we predicted participant production of the Spanish subjunctive would surpass the English passive voice for both grades. The subjunctive in 
Spanish emerges early with verbs of volition as those represented in the BESA assessment. The English passive voice is more abundant in written English, and it is less common than the Spanish subjunctive in oral interactions. Given the formal complexity of passive sentences, we anticipated difficulties in its production for both KDG and G1 when compared to the L1 subjunctive.

We hypothesized children would be more accurate in their progressive production overall than for the English passive or the Spanish subjunctive production. We based this prediction on Cummins' common underlying proficiency (CUP) hypothesis and frequency effects of environment input $[7,56]$. Applied to grammatical development, the CUP hypothesis predicts positive transfer of grammatical knowledge between structures with similar surface features in bilinguals. There is also the issue of interdependence between the L1 and the L2 and not necessarily only with structures sharing similar features [57]. Assuming a child has no developmental delays in the first language, that child should relate L1 knowledge and skills to the L2. Children's grammatical development of the progressive would be frequently reinforced given similar surface features in both languages and continuous use of the L1.

With regards to the third research question, we anticipated there would be developmental production differences between grades. Given decreased exposure to the L1 subjunctive at the onset of formal L2 instruction, further exacerbated by the low frequency of English subjunctive leading to less CUP transfer, we foresaw group differences with lower accuracy in the G1 group for the L1 subjunctive compared with the KDG group for the same structure. We hypothesized overall production to be higher in G1 with passives with regards to KDG due to English exposure at school for an additional academic year.

\subsection{Participants}

Two groups of sequential heritage children (native Spanish, English learners) participated in the study. There was a KDG group $(n=25)$ and a G1 group $(n=20)$. All participants were from one school district in rural northern Florida. They attended public schools where English was the language of instruction and were enrolled in ESOL classes during the regular school day. The sample was comprised of 28 girls and 17 boys. At the onset of the study age ranged from 60 to 83 months, with a mean of $69.27(S D=5.70)$.

Demographic information was collected early from participating parents through phone interviews at the beginning of the study in September of the academic year and once they had returned consent forms. Interviews revealed that the percentage of families with Spanish use at home was $55.1 \%$. The mean percentage of English use was 8\%. In all, 36.3\% of interviewed parents reported speaking both languages at home at one point. Three of the interviewed parents reported speaking no Spanish $(0 \%)$ at all and mentioned they conducted all interactions at home in English, though the heritage children kept in frequent contact with grandparents using Spanish mostly on weekends or over summer months.

Parents also reported that sometimes children spent time interacting with a Spanish-speaking adult in the afternoon, after school dismissal and until parents returned from work. This informal child-care worker was a member of the community who the parents had entrusted to care for their children during that time. Older siblings were involved in some cases with homework completion activities with the younger HSs during the week. As revealed by the parents, sibling interactions were usually bilingual. The children were then exposed to L1 conversations with parents, grandparents and other adult L1 speakers. Some practiced the L2 with older siblings for homework-related activities. Some of the families mentioned they also spoke different languages aside from Spanish. Some reported oral use of a Central American indigenous language such as Mizteco or Huasteca (9\%). Some of the children were then exposed to English at school, Spanish and English at home plus oral narratives in that indigenous language. Over the weekend, $75 \%$ of the children were exposed to Spanish printed materials through Sunday school instruction at the local church. Table 2 displays the socio-demographic characteristics of participants $(N=45)$. 
Table 2. Socio-Demographic Characteristics of Participants $(N=45)$.

\begin{tabular}{cccccc}
\hline & $N$ & $\%$ & $N$ & $\%$ \\
\hline Gender & & & Parent Education \\
Male & 17 & 37.8 & Less than high school & 33 & 73.3 \\
Female & 28 & 62.2 & High school diploma & 10 & 22.2 \\
Lunch Status & & & College & 2 & 4.4 \\
Free & 43 & 95.6 & SD & SD \\
Reduced & 2 & 4.4 & Percentage of Spanish Use & 55.1 & 11.7 \\
Grade & & & Percentage of English Use & 8 & 4.4 \\
KDG & 25 & 55.6 & Both & 36.3 & 18.5 \\
G1 & 20 & 44.4 & Child Age & $72 \mathrm{mo}$ & 9.8 \\
\hline
\end{tabular}

KDG: Kindergarten; G1: grade 1; mo: months.

\subsection{Procedures}

Standard BESA scoring procedures of the cloze task assign a 1 to a correct response in the target language and a 0 to all other responses. In order to analyze grammatical production in greater detail, responses to the BESA cloze item task were analyzed via researcher created codes, defined in a codebook and coding flowcharts. Numeric codes did not follow BESA scoring procedures and were created specifically to reflect the research questions presented here. Four codes were defined a priori and two codes were added upon preliminary examination of the data. All codes were designed to be mutually-exclusive, so that each response received only one code, reflecting a continuum of production accuracy as an ordinal level measure.

A priori, codes included: Target Structure or correct production. Partial Structure or emerging production, Off-Target Response in the form of root infinitives [9] or nominal substitutions, and No Response. The two codes added to the codebook after a visual analysis of raw data were: Translation and Alternate Structure. Tables 3 and 4 present percentage inter-coder agreement and examples of responses for the English progressive and the Spanish present subjunctive. Definitions and examples of the Translation and Alternate Structure codes are given in Section 4 in tandem with presenting our findings of these codes. Data were analyzed descriptively for proportions of responses per code. Children's responses were further compared using independent and paired $t$-tests.

We predicted high occurrence of progressive forms in English, a language in which the progressive form is obligatory to express simultaneous meaning. In Spanish we expected the progressive to occur in fewer contexts given that the simple present can also reference a progressive action or habitual action. We predicted high occurrence of the subjunctive in Spanish, as it emerges early in L1 Spanish with verbs of volition, as those presented in the BESA assessment. High occurrence of Spanish subjunctive would contrast with the formally complex English passive voice and the less-used progressive form in everyday Spanish.

Table 3. Sample of Coded Responses-English Present Progressive.

\begin{tabular}{ccc}
\hline English Present and Past Progressive & Coder \% Agreement & Example Responses \\
\hline Target Structure & $98 \%$ & was riding, are skating \\
Partial Structure & $99 \%$ & riding, skating \\
Off Target Response & $98 \%$ & ride, skate \\
No response & $100 \%$ & - \\
\hline
\end{tabular}

Table 4. Sample of Coded Responses-Spanish Present Subjunctive.

\begin{tabular}{ccc}
\hline Spanish Subjunctive & Coder \% Agreement & Example Responses \\
\hline Target Structure & $94 \%$ & salgan 'they leave', se lave 'she wash herself' \\
Partial Structure & $100 \%$ & salan 'leave', lave 'wash' \\
Off Target Response & $95 \%$ & salen 'leave', lava 'wash' \\
No response & $100 \%$ & - \\
\hline
\end{tabular}




\section{Results}

Translations were the least frequently observed production responses comprising 15 of the 945 total responses. No child translated from English to Spanish. All translations occurred from Spanish to English, perhaps as a response to the environment surrounding testing procedures in which English prevailed as the socially dominant language. Responses to nine Spanish progressives and six Spanish subjunctives were translated to English. Due to the limited occurrence of translations, we decided not to further analyze accuracy of translated responses.

The Alternate Structure code was defined as occurring when children used a different verb tense or verb phrase structure than the targeted tense and structure, but the production remained grammatically accurate due to the context of the prompt and stimulus picture. For example, in the English progressive, a child's response "They turn on the T.V." was coded as an Alternate Structure while the targeted response would be, "They are watching T.V." This was the only instance of an Alternate Response in the English progressive responses.

Similarly, for the Spanish progressive targets, responding with a root infinitive as detailed in Grinstead et al. [9] or a generic third person, as seen in the BESA, ¿Qué hace el niño? Lee un cuento 'He reads a book', instead of está leyendo 'What are the children doing?' 'They read a book.' (instead of 'They are reading a book') was coded as an Alternate Response. This pattern of response occurred in four out of 125 total KDG Spanish progressive responses (G1 children did not exhibit this pattern within their 100 responses).

In English passive responses, an Alternate Response was coded when children refrained from using the passive voice and used the active voice, for example, stating "The girl is pushing the boy", instead of, "The boy was pushed by the girl". An Alternate Response was also assigned when children used the word got within their verb phrase instead of conjugating the to be copula to the accurate past-tense (e.g., got pushed instead of was pushed or were pushed [25]). All the alternate responses were grammatically correct.

Of all targeted structures, children exhibited Alternate Responses the most often with English passives (18 out of 225 total responses), indicating possible avoidance or production of the passive and resorting to a response in the active voice instead. Finally, responses to prompts targeting the Spanish subjunctive, whose structure ignored a mandatory formulation by demonstrating a [tener que + infinitive] ('to have to' + infinitive) formulation or by describing the picture were coded as Alternative Responses. The Alternate Response code applied to three out of 270 subjunctive prompt responses. Overall, Alternate Responses were second in order often occurring response with a total of 26 out of 945 responses. A summary of all observed, coded responses of the BESA morphosyntax portion is provided next in Table 5.

Table 5. Totals of Coded Responses.

\begin{tabular}{cccc}
\hline Linguistic Structure & (Code) & $\boldsymbol{n}$ & $\mathbf{\%}$ \\
\hline Target Structure & $(5)$ & 368 & 38.94 \\
Partial Structure & $(3)$ & 26 & 2.75 \\
Off Target Response & $(1)$ & 15 & 1.59 \\
No response & $(0)$ & 140 & 14.81 \\
Total & & 945 & 100 \\
\hline
\end{tabular}

Note: The numeric code for each production token is given in parentheses.

\subsection{Present Progressive in English and Spanish: A Comparison between Kindergarten and Grade 1}

A comparison of Spanish progressive mean prompts between grades did not reach statistical significance $(t(34.47)=-0.56, p=0.58)$. In Spanish, KDG children produced $53 \%$ of all progressive forms correctly (Table 6). Correct production of progressive forms in G1 was 55\% (Table 7). Inaccurate responses were further analyzed for evidence of emerging development. Emergent development was 
attributed to partially correct responses (e.g., production of the correct gerund or a root infinitive in absence of the auxiliary verb, versus an off-target production or no response at all). In Spanish, KDG children produced $29 \%$ emergent Spanish progressives, i.e., only gerunds, versus $21 \%$ of children in Grade 1. Off-target and no responses appeared to increase from KDG to G1, from 13\% to 19\%, as reflected in Tables 6 and 7, but this change in production rate was not significant (off-target $t(43)=0.16$, $p=0.88$; non-response $t(43)=1.20, p=0.24)$.

Table 6. KDG Proportion of Responses for Spanish-English Structures.

\begin{tabular}{cccc}
\hline \multicolumn{3}{c}{ Spanish } \\
\hline Items & $\begin{array}{c}\text { Progressive Tense } \\
\text { No of Responses }\end{array}$ & Items & $\begin{array}{c}\text { Subjunctive } \\
\text { No of Responses }\end{array}$ \\
\hline Aux. + Gerund & $66 / 125(52.8 \%)$ & Subj. + Tense & $52 / 150(34.7 \%)$ \\
Gerund Only & $35 / 125(28.8 \%)$ & Subjunctive Only & $14 / 150(9.3 \%)$ \\
Off Target & $8 / 125(6.4 \%)$ & Off Target & $55 / 150(36.7 \%)$ \\
No Production & $8 / 125(6.4 \%)$ & No Production & $22 / 150(14.7 \%)$ \\
Coded Average & 3.74 & Coded Average & 2.51 \\
\hline & \multicolumn{3}{c}{ English } \\
\hline Items & Progressive Tense & Items & Passive \\
& No of Responses & Aux. + Past Participle & $27 / 125(21.6 \%)$ \\
Aux. + Gerund & $37 / 125(29.6 \%)$ & PP $/$ Emerging & $6 / 125(4.8 \%)$ \\
Gerund Only & $38 / 125(30.4 \%)$ & Off Target & $54 / 125(43.2 \%)$ \\
Off Target & $28 / 125(22.4 \%)$ & No Production & $28 / 125(22.4 \%)$ \\
No Production & $21 / 125(16.8 \%)$ & Coded Average & 1.98 \\
Coded Average & 2.65 & & \\
\hline
\end{tabular}

Table 7. Grade 1 Proportion of Responses for Spanish-English Structures.

\begin{tabular}{cccc}
\hline \multicolumn{3}{c}{ Spanish } \\
\hline Items & $\begin{array}{c}\text { Progressive Tense } \\
\text { No of Responses }\end{array}$ & Items & $\begin{array}{c}\text { Subjunctive } \\
\text { No of Responses }\end{array}$ \\
\hline Aux. + Gerund & $55 / 100(55.0 \%)$ & Subj. + Tense & $60 / 120(50 \%)$ \\
Gerund Only & $21 / 100(21.0 \%)$ & Subjunctive Only & $8 / 120(6.7 \%)$ \\
Off Target & $7 / 100(7.0 \%)$ & Off Target & $33 / 120(27.5 \%)$ \\
No Production & $12 / 100(12.0 \%)$ & No Production & $14 / 120(11.7 \%)$ \\
Coded Average & 3.55 & Coded Average & 3.07 \\
\hline & \multicolumn{3}{c}{ English } \\
Items & Progressive Tense & Items & Passive \\
\hline Nux. + Gerund & $41 / 100(41.0 \%)$ & Aux. + Past Participle & $30 / 100(30.0 \%)$ \\
Gerund Only & $36 / 100(36.0 \%)$ & PP $/$ Emerging & $11 / 100(11.0 \%)$ \\
Off Target & $12 / 100(12.0 \%)$ & Off Target & $28 / 100(28.0 \%)$ \\
No Production & $11 / 100(11.0 \%)$ & No Production & $23 / 100(23.0 \%)$ \\
Coded Average & 3.25 & Coded Average & 2.43 \\
\hline
\end{tabular}

Contrary to Spanish, English progressive non-target or no response items were less frequent in G1 compared to KDG (Tables 6 and 7). However, a comparison of means between grades did not reach significance $(t(43)=1.61, p=0.12)$. In English, KDG children produced $30 \%$ of all progressive forms correctly compared with $41 \%$ correct production in G1. Partially correct responses also differed between grades. In KDG 30\% of all progressive forms were produced partially correct, as an emerging structure. The percentage of partially correct forms was significantly different in G1 with 36\% production of partially correct, emerging structure forms. A within subjects, between language comparison of means to all progressive prompts found children were overall more accurate in LI Spanish than in L2 English, 
$(t(44)=-3.12, p<0.01)$. In addition, the production rate of accurate responses to progressives was higher in Spanish $(t(44)=-2.99, p<0.01)$. Young HSs were more accurate in L1 production of the progressive form.

\subsection{English Passive Voice: Kindergarten and Grade 1}

A between grade comparison on the English passive structure did not reach statistical significance $(t(43)=1.32, p=0.20)$. Similarly, a grade comparison of production rates for accurate productions $(t(43)=1.24, p=0.22)$, emerging structure responses $(t(43)=1.21, p=0.24)$ and no-response $(t(43)=0.07, p=0.94)$ did not show grade differences either.

Despite no significant changes between grades, G1 participants produced more target and emerging structures and fewer off-target and no responses of the English passives. In KDG, target production of English passives was 22\%; and passive accuracy in the G1 group was 30\%. G1 children's emergent, or partially correct passive production was $6 \%$ points higher than the KDG group, producing $11 \%$ of passives partially accurate. Partially accurate English passive responses were defined as production of the past participle in absence of the auxiliary form, failure to produce an accurate participle in absence of any other error (e.g., The baby was carry by the father), or failure to reverse the order of the agents. Children's average accuracy on English progressive tense ('-ing') was higher than their average accuracy on English passive $(t(44)=3.73, p=0.001)$.

\subsection{Spanish Subjunctive: Kindergarten and Grade 1}

Production of accurate Spanish Subjunctive verbs appeared to be greater in G1 compared to KDG, with $50 \%$ of G1's productions accurate versus KDG's $35 \%$. Production of non-response and off-target responses demonstrated significantly lower occurrence in G1, as seen in Table 7. This finding supported grade differences benefitting the higher grade. Specifically, non-target and off-target forms were significantly different between grades, with 52\% in KDG and 39\% in G1 (Tables 6 and 7). Partially accurate or emergent Spanish subjunctives were defined as production of the verb root and subjunctive mood in absence of the appropriate tense inflection (e.g., comas for coman ('that you eat' instead of 'that they eat', or salan for salgan ('that leave', instead of 'that they leave'). There did not appear to be any major difference between grades regarding emergent production of Spanish subjunctives, with $10.00 \%$ KDG and $7.50 \%$ of G1.

A between grade comparison of average accuracy on Spanish subjunctive did not reach statistical significance $(t(43)=1.45, p=0.15)$. However, a comparison of the response rate for accurate responses between grades approached significance $(t(43)=1.71, p=0.09)$. A within subjects, between language comparison of means of all English passive and Spanish subjunctive prompts found children were more accurate in LI Spanish than L2 English, $(t(44)=-2.27, p<0.05)$ supporting the prediction that the Spanish subjunctive's high frequency of use with verbs of volition would favor L1 subjunctive production compared to the complex passives in the L2. In addition, the production rate of accurate Spanish subjunctives was higher than for English passives $(t(44)=-3.82, p<0.001)$. Children's Spanish progressive mean, however, was higher than their Spanish subjunctive $(t(44)=3.86, p<0.001)$.

\subsection{Summary of Key Findings}

Similar to previous research HSs with early onset of bilingualism produced more responses in the home language, L1 Spanish, regardless of structure [16,58-60]. Progressives were significantly more accurate in L1 Spanish, which did not support the hypothesis that young HSs would be more productive with the English progressive form due to semantic differences in progressive use in the two languages. Substitution of progressive form in Spanish for a root infinitive or present tense was not frequent. It occurred in four out of 125 total KDG Spanish progressive responses (G1 children did not exhibit this pattern within their 100 responses).

As predicted, Spanish subjunctive's production surpassed that of the English passive voice, the most complex structure of all three structures. Grade differences did not imply group differences. 
Overall, G1 HSs produced more targets for both Spanish structures. Although there were no significant differences between grades on English production, all descriptive patterns indicate that G1 outperformed the KDG group, producing greater on-target responses and fewer errors overall.

Interestingly, the general proportions of responses tended to reflect similar patterns between grades, but differences emerged between structures with high frequency of use in both languages (progressives) versus structures with higher frequency of use in only one language (English Passive Voice in L2 and Spanish Subjunctive in L1). With regard to Spanish and English progressives, children produced mostly accurate and partially accurate responses regardless of grade (e.g., KDG Spanish 81\%; G1 Spanish 76\%; KDG English 60\%; G1 English 77\%). The progressive form had higher production in the L1.

However, for more complex and later-developing structures (English passive and Spanish subjunctive), children produced mostly accurate and non-target responses-instead of partially accurate responses (e.g., KDG Spanish subjunctive 71\%; G1 Spanish subjunctive 78\%; KDG English passive $65 \%$; G1 English passive 58\%). This finding is interpreted as supporting our hypothesis that structures with similar linguistic features and similar frequency of use across languages would be supported by a common underlying proficiency to be produced with greater accuracy than structures that are not used with equal frequency across languages. The larger amount of non-target responses for the subjunctive and passives also points at developmental stages in the acquisition of more complex structures in children. We now proceed to discuss findings in more detail in the following section.

\section{Discussion}

Presently, there is no definite or clear characterization of the linguistic outcomes of young bilinguals. It is known that HSs exhibit degrees of variability in language knowledge which are related to the family and school linguistic contexts. However, this study makes an important contribution in describing linguistic production of young HSs with different grammatical structures when they are in the early grades of social majority language instruction and with continuous L1 access. We found no signs of significant differences between the two groups of HSs in KDG and G1. The children did not show significantly less accuracy on grammatical forms in the L1 or the L2.

Delayed exposure to L2 English (school entrance in KDG for most HSs) and continuous L1 use at home and in the community accompanied L1 maintenance at ages 5-6, [14,61]. As expected, due to high frequency of subjunctive use with verbs of volition, children's production of the Spanish subjunctive at ages 5-6 was robust, [20]. Spanish subjunctive KDG production was $35 \%$ in KDG vs. $50 \%$ in G1. The early use of L1 Spanish subjunctive was abundant in this group of participants in spite of daily L2 English instruction and in the absence of formal L1 schooling.

By contrast accuracy in production of the passive voice from KDG to G1 was not as strong as the subjunctive. We anticipated the formal complexity of the passive which imposes knowledge of argument structure [10] would not necessarily correlate with higher accuracy in production in G1, and this was the case with the young participants. As to the English progressive, accurate production increased in the G1 participants, but the cross-sectional sample was more accurate in L1 progressive forms. The BESA Spanish progressive section included dynamic verbs (as opposed to verbs denoting states, conditions) which seemed to have facilitated use of the structure in the L1 with a progressive shape in both grades. Some of the Spanish verbs included in the BESA progressive section (nadando 'swimming', caminando 'walking') depict lively actions favoring the use of estar and the gerund.

Continued use of L1 structures in the young HSs also reflects access to rich input at home from parents and some benefits of L1 vocabulary input in school. All G1 participants had already experienced a strong vocabulary intervention through the BLOOM project during the KDG year; whereas, the KDG group had not participated in the intervention the previous academic year. As part of the project, Spanish L1 was used for L2 acquisition in the e-books presented to them three times a week (project's vocabulary treatment) during 20 weeks. The e-books contained vocabulary instruction through explanation in Spanish, repetitions, checks for understanding, and highlighted Spanish 
morphology. Though Spanish was used in the e-books in an initial stage of the e-book vocabulary intervention, reinforcement of vocabulary items and global word comprehension checks were provided only in English. Spanish L1 was a bridge for L2 vocabulary intervention during the 20-week literacy period. The use of both languages in the KDG year gave G1 children opportunities for ample L1 and L2 practice.

Although most parents interviewed in the participating sample had not concluded high school (73.3\%) and communicated less in English, they usually read in Spanish to the children during the week, and the L1 was also used in community practices on weekends. All children attended schools with regular English instruction, but had frequent oral interactions with bilingual educators in Spanish during the school day in a school environment that included many Spanish speakers. Our investigation supports views that maintaining proficiency in Spanish requires a combination of home and school instruction $[62,63]$ with daily Spanish communication in the household. In this case, children had informal interactions in Spanish with bilingual school educators.

Nonetheless, there were also signs of L2 grammatical development for both English structures, the progressive and the passive, at ages 5-6 [4,17]. Yet, no grade difference was detected with statistical testing. KDG HSs produced $22 \%$ of passives correct vs. $30 \%$ of G1 HSs. Cross-linguistic similarity in the structure, early age-of-acquisition of the progressives and verb selection in the BESA test (walking, skating, swimming, riding) may have facilitated progressives' overall production in our sample. This was evidenced by a higher proportion of partially correct responses as compared to non-target responses in the more complex English passives [64].

Results support findings that as a group, young HSs demonstrated higher grammatical accuracy in the home language, Spanish, while learners are early in the process of English second language acquisition $[65,66]$. However, our findings also indicate English grammatical development begins early, with kindergarteners demonstrating higher levels of emerging grammatical production in English as compared to Spanish.

Our findings support results from Collins, O' Connor, Suárez-Orozco, Nieto-Castañón, and Toppelberg in the sense that a specific linguistic context can facilitate language use [67]. As the young HSs of the study had access to both English and Spanish in their interactions at home and school, they benefited from the input received in both languages. Moreover, all children lived in neighborhoods with high numbers of Spanish speakers, and most of the adults the children talked to in Spanish were native speakers of the language. Some of the school educators were also Spanish-speaking. Therefore, children were exposed to both languages regularly, and were able to communicate in both languages in a variety of situations.

When comparing the G1 group to the KDG one on grammatical accuracy in structurally similar (progressive form in Spanish and English) and dissimilar (subjunctives and passives) constructions in Spanish or English, different patterns surfaced. G1 Spanish grammatical accuracy was similar compared to the KDG group for the grammatically similar, progressive form. However, due to the nature of the BESA assessment in which examinees respond to a specific prompt via pictures, we cannot make definite claims that L1 progressive production is favored to L2 production of the same structure. A more naturalistic and open test such as oral narratives or other assessments targeting young heritage spontaneous speech could yield different results.

The G1 group demonstrated higher accuracy in the later-developing, dissimilar form, the Spanish subjunctive mood, than the KDG group. This could be a sign that use of the subjunctive with Spanish verbs of volition is strong and stable in the speech of young HSs in spite of formal English instruction. G1 English grammatical accuracy was higher than KDG accuracy for both the structurally similar (progressives) and the dissimilar forms (passives) across languages. This may indicate that as children are exposed to English through formal education, greater exposure to English does not continue to support all types of Spanish productions [31], but further research is needed to investigate it. 


\section{Conclusions}

This study contributes to expand the body of research that has examined production patterns of young HSs in the L1 and the L2 and the interrelationship between the two languages in language development, $[23,61,68]$. We used the BESA instrument, which was specifically designed to assess bilingual Spanish-English child language development, and is therefore an authentic bilingual child assessment to evaluate production in children. We believe findings of the morphosyntax production section related herein indicate that instruction in the L2 does not necessarily equate with L1 loss when HSs begin instruction in the majority language. This applies to both the Spanish present progressive and the subjunctive mood.

Even if the participating children did not have access to formal L1 schooling, both languages had remained active at home, in the community, and at school. The children went to school in English and talked to their parents, caregivers and some school educators in Spanish. At home, children interacted with older siblings in English and in Spanish for completion of homework assignments. Their high Spanish proficiency and continuous input in the L1 supported grammatical structure production, even when children were attending a regular English school.

We agree that a general characterization of the linguistic abilities of young bilinguals is difficult to define according to existing findings, and that there is variability in their production patterns across the different grades. We believe additional research with other structures besides the subjunctive, passives and the progressive can help in describing young heritage speaker linguistic production further. It would also be interesting to examine the distinct influence that family members (parents, siblings, grandparents, caregivers) may have on young heritage linguistic development. The results of our study are limited to linguistic production in the L1 and L2 in KDG and G1, but not beyond. We still know little about L1 production in young HSs between the ages of 7-18. These age groups should also be investigated. There is no doubt that HSs will continue to attract attention over the next years, and that their home and school learning practices will be documented in future studies.

Acknowledgments: The research reported here was supported by the Institute of Education Sciences, U.S. Department of Education, through Grant R305A130460. The opinions expressed are those of the authors and do not represent views of the Institute or the U.S. Department of Education. We are grateful to all child participants and their parents for their support in carrying out this project. All errors remaining are our own.

Author Contributions: E.R. conceived and designed the study, analyzed the data, and contributed to writing the paper. K.B. contributed to study design, performed the experiments, analyzed the data, and contributed to writing the paper. C.W. and G.S. contributed to data management and analyses, as well as writing the paper.

Conflicts of Interest: The authors declare no conflict of interest.

\section{References}

1. Valdés, G. Introduction. Spanish for native speakers, Volume I. In AATSP Professional Development Series Handbook for Teachers K-16; Harcourt College: New York, NY, USA, 2000; pp. 1-29.

2. Montrul, S. Morphological errors in Spanish second language learners and heritage speakers. Stud. Second Lang. Acquis. 2011, 33, 163-192. [CrossRef]

3. Montrul, S. The Acquisition of Heritage Languages; Cambridge University Press: Cambridge, UK, 2016.

4. Benmamoun, E.; Montrul, S.; Polinsky, M. Heritage languages and their speakers: Opportunities and challenges for linguistics. Theor. Linguist. 2013, 39, 129-181. [CrossRef]

5. Montrul, S. Incomplete acquisition of tense-aspect and mood in Spanish heritage speakers. Int. J. Biling. 2009, 13, 239-269. [CrossRef]

6. Pérez-Leroux, A.T. The acquisition of mood selection in Spanish relative clauses. J. Child Lang. 1998, 25, 585-604. [CrossRef] [PubMed]

7. Hoff, E.; Welsh, S.; Place, S.; Ribot, K.M. Properties of dual language input that shape bilingual development and properties of environments that shape dual language input. In Input and Experience in Bilingual Development: Trends in Language Acquisition Research; Gruter, T., Paradis, J., Eds.; John Benjamins Publishing Company: Amsterdam, The Netherlands, 2014; Volume 13, pp. 119-140. 
8. Jackson, C.W.; Schatschneider, C.; Leacox, L. Longitudinal analysis of receptive vocabulary growth in young Spanish English-speaking children from migrant families. Lang. Speech Hear. Serv. Sch. 2014, 45, 40-51. [CrossRef] [PubMed]

9. Grinstead, J.; Baron, A.; Vega-Mendoza, M.; De la Mora, J.; Cantú-Sánchez, M.; Flores, B. Tense marking and spontaneous speech measures in Spanish specific language impairment: A discriminant function analysis. J. Speech Lang. Hear. Res. 2013, 56, 1-12. [CrossRef]

10. Pinker, S. Learnability and Cognition: The Acquisition of Argument Structures; MIT Press: Cambridge, MA, USA, 1989.

11. Keating, G.D.; VanPatten, B.; Jegerski, J. Who was walking on the beach? Anaphora resolution in Spanish heritage speakers and adult second language learners. Stud. Second Lang. Acquis. 2011, 33, 193-221. [CrossRef]

12. Montrul, S.; Perpiñán, S. Assessing differences and similarities between instructed L2 learners and heritage language learners in their knowledge of Spanish Tense-Aspect and Mood (TAM) Morphology. Herit. Lang. J. 2011, 8, 90-133.

13. Montrul, S.; Sánchez-Walker, N. Differential object marking in child and adult Spanish heritage speakers. Lang. Acquis. 2013, 20, 109-132. [CrossRef]

14. Pascual y Cabo, D.; Gómez, I. Preposition stranding in Spanish as a heritage language. Herit. Lang. J. 2015, 12, 186-209.

15. Potowski, K.; Jegerski, J.; Morgan-Short, K. The effects of instruction on linguistic development in Spanish heritage language speakers. Lang. Learn. 2009, 59, 537-579. [CrossRef]

16. Cuza, A.; Frank, J. On the role of experience and age-related effects: Evidence from the Spanish CP. Second Lang. Res. 2014, 31, 3-28. [CrossRef]

17. Rothman, J. Heritage speaker competence differences, language change and input type: Inflected infinitives in heritage Brazilian Portuguese. Int. J. Biling. 2007, 11, 359-389. [CrossRef]

18. Rodríguez, E.; Reglero, L. Heritage and L2 processing of person and number features: Evidence from Spanish subject-verb agreement. EuroAm. J. Appl. Linguist. Lang. 2015, 2, 11-30. [CrossRef]

19. Castilla-Earls, A.; Pérez-Lereoux, A.T.; Restrepo, M.A.; Gaile, D.; Ziqiang, C. The complexity of the Spanish subjunctive in bilingual children with SLI. Lang. Acquis. 2016, 1-13. [CrossRef]

20. Silva-Corvalán, C. Bilingual Language Acquisition: Spanish and English in the First Six Years; Cambridge Approaches to Language Contact; Cambridge University Press: Cambridge, UK, 2014.

21. Cuza, A.; Pérez-Tattam, R. Grammatical gender selection and phrasal word order in child heritage Spanish: A feature re-assembly approach. Biling. Lang. Cogn. 2015, 19, 50-68. [CrossRef]

22. Lardière, D. Feature-assembly in second language acquisition. In The Role of Formal Features in Second Language Acquisition; Liceras, J., Zobl, H., Goodluck, H., Eds.; Lawrence Erlbaum Associates: New York, NY, USA, 2008; pp. 106-140.

23. Montrul, S.; Potowski, K. Command of gender agreement in school-age Spanish-English bilingual children. Int. J. Biling. 2007, 11, 301-328. [CrossRef]

24. Georgi, A.; Pianesi, F. Tense and Aspect: From Semantics to Morphosyntax; Oxford University Press: New York, NY, USA, 1997.

25. Mitkovska, L.; Bužarovska, E. An alternative analysis of the English get-past participle constructions: Is get all that passive? J. Engl. Linguist. 2011, 40, 196-215. [CrossRef]

26. Collins, P.C. Get-passives in English. World Engl. 1996, 15, 43-56. [CrossRef]

27. Fleisher, N. The origin of passive get. Engl. Lang. Linguist. 2006, 10, 225-252. [CrossRef]

28. Huddleston, R.; Geoffrey, K.P. The Cambridge Grammar of the English Language; Cambridge University Press: Cambridge, UK, 2002.

29. De Garavito, J.B.; Valenzuela, E. Eventive and stative passives in Spanish L2 acquisition: A matter of aspect. Biling. Lang. Cogn. 2008, 11, 323-336. [CrossRef]

30. De Garavito, J.B. The syntax of Spanish multifunctional clitics and near-native competence. Ph.D. Thesis, McGill University, Montréal, QC, Canada, January 1999.

31. Mendikoetxea, A. Clitic impersonal constructions in Romance: Syntactic features and semantic interpretation. Trans. Phil. Soc. 2008, 106, 290-336. [CrossRef]

32. Bardovi-Harlig, K. Tense and Aspect in Second Language Acquisition: Form, Meaning and Use; Young, R., Ed.; Language Learning Monograph Series; Blackwell: Malden, MA, USA, 2000. 
33. Squartini, M. Verbal Periphrasis in Romance: Aspect, Actionality and Grammaticalization; Mouton de Gruyter: Berlin, Germany, 1998.

34. Zagona, K. Verb Phrase Syntax: A Parametric Study of English and Spanish; Springer Science and Business Media: Dordrecht, The Netherlands, 1988.

35. Zagona, K. The Syntax of Spanish; Cambridge University Press: Cambridge, UK, 2002.

36. Wanner, A. Deconstructing the English Passive; Walter de Gruyter: Berlin, Germany, 2009.

37. De Villiers, J.G.; De Villiers, P.A. Cross-sectional study of the acquisition of grammatical morphemes in child speech. J. Psycholinguist. Res. 1973, 2, 267-278. [CrossRef] [PubMed]

38. Dulay, H.; Burt, M. A new approach to discovering universal strategies of child second language acquisition. In Developmental Psycholinguistics: Theory and Applications; Dato, D., Ed.; Georgetown University Press: Washington, DC, USA, 1975; pp. 209-233.

39. Krashen, S.; Scarcella, R. On routines and patterns in language acquisition and performance. Lang. Learn. 1978, 28, 283-300. [CrossRef]

40. Pérez-Cortes, S. The interpretation of present progressive aspectual features by L2 Spanish learners and heritage language speakers. Ariz. Work. Pap. SLA Teach. 2012, 19, 36-55.

41. Cuza, A. On the L1 attrition of the Spanish present tense. Hispania 2010, 93, 256-272. [CrossRef]

42. Blake, R. The Acquisition of Mood Selection among Spanish-Speaking Children: Ages 4 to 12. Ph.D. Thesis, University of Texas, Austin, TX, USA, 1980.

43. Collantine, J. The acquisition and teaching of the Spanish subjunctive: An update on current findings. Hispania 2010, 93, 39-51. [CrossRef]

44. López-Ornat, S.; Fernández, A.; Gallo, P.; Mariscal, S. La Adquisición de la Lengua Española; Siglo XXI: Madrid, Spain, 1994.

45. Dabrowska, E.; Street, J. Individual differences in language attainment: Comprehension of passive sentences by native and non-native English speakers. Lang. Sci. 2005, 28, 604-615. [CrossRef]

46. Street, J.A.; Dąbrowska, E. More individual differences in language attainment: How much do adult native speakers of English know about passives and quantifiers? Lingua 2010, 120, 2080-2094. [CrossRef]

47. Doh Park, S. Parameters of Passive Construction in English and Korean. Ph.D. Thesis, Cornell University, New York, NY, USA, June 2005.

48. Ferreira, F. The misinterpretation of noncanonical sentences. Cogn. Psychol. 2003, 47, 164-203. [CrossRef]

49. Deen, K.U. The acquisition of the passive. In Handbook of Generative Approaches to Language Acquisition; de Villiers, J., Roeper, T., Eds.; Springer: Dordrecht, The Netherlands, 2011; pp. 155-187.

50. Peña, E.D.; Gutiérrez-Clellen, V.F.; Iglesias, A.; Goldstein, B.A.; Bedore, L.M. Bilingual English-Spanish Assessment; AR-Clinical Publications: San Rafael, CA, USA, 2014.

51. Dunn, L.M. Peabody Picture Vocabulary Test-Revised; American Guidance Service: Circle Pines, MN, USA, 2007.

52. Woodcock, R.W. Woodcock Reading Mastery Tests, 3rd ed.; Pearson: San Antonio, TX, USA, 2011.

53. Dunn, L.; Lugo, S.; Padilla, R.; Dunn, L.M. Test de Vocabulario en Imágenes [Peabody Picture Vocabulary Test]; Peabody; American Guidance Service: Circle Pines, MN, USA, 1986.

54. Bialystok, E.; Luk, G.; Peets, K.F.; Yang, S. Receptive vocabulary differences in monolingual and bilingual children. Biling. Lang. Cogn. 2010, 13, 525-531. [CrossRef] [PubMed]

55. Wood, C.; Peña, V. Lexical considerations for standardized vocabulary testing with young Spanish-English speakers. Contemp. Issues Commun. Sci. Dis. 2015, 42, 202-214.

56. Cummins, J. The role of primary language development in promoting educational success for language minority students. In Schooling and Language Minority Students: A Theoretical Framework; Leyba, C., Ed.; California State University: Los Angeles, CA, USA, 1994; pp. 3-49. [CrossRef]

57. Castilla, A.P.; Restrepo, M.A.; Perez-Leroux, A.T. Individual differences and language interdependence: A study of sequential bilingual development in Spanish-English preschool children. Int. J. Biling. Educ. Biling. 2009, 12, 565-580. [CrossRef]

58. Foote, R. Age of acquisition and proficiency as factors in language production: Agreement in bilinguals. Biling. Lang. Cogn. 2010, 13, 99-118. [CrossRef]

59. Kohnert, K.J.; Bates, E.; Hernández, A.E. Lexical-semantic production and cognitive processing in children learning Spanish and English. J. Speech Lang. Hear. Res. 1999, 42, 1400-1413. [CrossRef] [PubMed] 
60. Montrul, S.; Davidson, J.; De la Fuente, I.; Foote, R. Early language experience facilitates the processing of gender agreement in Spanish heritage speakers. Biling. Lang. Cogn. 2014, 17, 118-138. [CrossRef]

61. Miller, L.; Cuza, A. On the status of tense and aspect morphology in child heritage Spanish: An analysis of accuracy levels. In Proceedings of the 2013 Generative Approaches to Second Language Acquisition Conference, Gainesville, FL, USA, 26-28 April 2013; Amaro, J.C., Judy, T., Pascual y Cabo, D., Eds.; Cascadilla Proceedings Project: Somerville, MA, USA, 2013; pp. 117-129.

62. Collins, B.A. Dual language development of Latino children: Effect of instructional program type and the home and school language environment. Early Child. Res. Q. 2014, 29, 389-397. [CrossRef] [PubMed]

63. Duursma, E.; Romero-Contreras, S.; Szuber, A.; Proctor, P.; Snow, C.; August, D.; Calderón, M. The role of home literacy and language environment on bilinguals' English and Spanish vocabulary development. Appl. Psycholinguist. 2007, 28, 171-190. [CrossRef]

64. Bland-Stewart, L.M.; Fitzgerald, S.M. Use of Brown's 14 grammatical morphemes by bilingual Hispanic preschoolers: A pilot study. Commun. Dis. Q. 2001, 22, 171-186. [CrossRef]

65. Bohman, T.M.; Bedore, L.M.; Peña, E.D.; Mendez-Pérez, A.; Gillam, R.B. What you hear and what you say: Language performance in early sequential Spanish English bilinguals. Int. J. Biling. Educ. Biling. 2010, 13, 325-344. [CrossRef] [PubMed]

66. Oller, D.K.; Eilers, R.E. Language and Literacy in Bilingual Children; Oller, K., Eilers, R., Eds.; Multilingual Matters: Buffalo, NY, USA, 2002.

67. Collins, B.A.; O’Connor, E.E.; Suárez-Orozco, C.; Nieto-Castañón, A.; Toppelberg, C.O. Dual language profiles of Latino children of immigrants: Stability and change over the early school years. Appl. Psycholinguist. 2014, 35, 581-620. [CrossRef] [PubMed]

68. Palermo, F.; Mikulski, A.M.; Fabes, R.A.; Martin, C.L.; Hanish, L.D. Cross-language associations and changes in Spanish-speaking preschoolers' English and Spanish academic abilities. Appl. Psycholinguist. 2016, 38, 347-370. [CrossRef]

(C) 2017 by the authors. Licensee MDPI, Basel, Switzerland. This article is an open access article distributed under the terms and conditions of the Creative Commons Attribution (CC BY) license (http:/ / creativecommons.org/licenses/by/4.0/). 